\title{
Ameliorative Role of Nutraceutical Quercetin and its Derivatives Against Cognitive Impairment Process Induced by Lead Exposure in Drosophila melanogaster(Fruit Fly) \\ B. S. Katsayal ${ }^{* 1}$, A. A. Lema ${ }^{* *}$, K. Jibrin", W. Nuraddeen ${ }^{* * *}$, E. M. Alexander ${ }^{* * * *}$ and N.H Mohammed ${ }^{* * * * * *}$
}

*Department of Biochemistry, Ahmadu Bello University, Zaria, Kaduna State, Nigeria

** Department of Biotechnology, University Sultan Zainal Abidin, Kuala Terengganu, Malaysia

**** Department of Biological Sciences, Al-Qalam University, Katsina, Katsina State, Nigeria

${ }^{* * * * *}$ Department of Zoology (Applied Entomology \& Parasitology), University of Jos, Plateau State, Nigeria

****** Department of Plant Biotechnology, Faculty of Bioresources and Food Industry, University Sultan Zainal Abidin, Terengganu Malaysia

\section{Abstract}

Cumulative lifetime lead $(\mathrm{Pb})$ exposure has been associated with accelerated declines in cognition through free radical generation and epigenetic effects.Several literature has established the link between lead exposure and neurodegenerative disorders.Harwich strain of drosophila Melanogaster were exposed to lead acetate for two weeks and the changes in impulse transmission through acetylcholinesterase and systemic redox state were assessed. In addition, molecular docking studies of acetylcholinesterase against quercetin was carried out. In silico toxicity, pharmacokinetics studies on quercetin were also carried-out. The data obtained showed alteration in function of antioxidant enzymes and molecules such as catalase, glutathione-S-transferase and glutathione. Up regulation of acetylcholinesterase activity was observed following treatment with quercetin. Molecular docking studies revealed quercetin to bind to both active and peripheral pocket of acetylcholinesterase. Pharmacokinetic studies show moderate solubility, high therapeutic index, excellent absorption capacity, hepatoprotective and non-mutagenic properties. Therefore, quercetin alongside other antioxidant molecules can play a vital role in preventing the onset of Alzheimer and antioxidant related disorders.

Keywords: Alzheimer; Antioxidant; Acetylcholinesterase; Neurodegeneration; Oxidative damage.

\section{Introduction}

Neurodegenerative disorders are agerelated neurological disorders associated with the progressive loss of neurons' structure and function $(1,2)$. Commonly known among these disorders include Alzheimer's disease, Parkinson's disease, the foam of dementia, and Huntington's disease ${ }^{(3)}$. Alzheimer's disease is the most predominant among the elderly and fully characterized by extracellular plaques of $\beta$-amyloid, hyperphosphorylated tau protein, and loss of cholinergic neurons leading to a behavioral loss and cognitive function ${ }^{(4)}$. Several hypotheses have been put forward to explain this disorder, but the cholinergic hypothesis, which described the involvement of acetylcholinesterase and butyrylcholinesterase and oxidative stress hypothesis, were more prominent ${ }^{(3,5)}$. Evidence has proven the neuroprotective role of acetylcholinesterase inhibitors in the clinical management of Alzheimer's diseases. Some of these inhibitors reported include donepezil, galantamine, tacrine, neostigmine, pyridostigmine, and physostigmine, among many other compounds and plant extracts ${ }^{(6,7)}$. The role of oxidative damage in the pathophysiology of Alzheimer's disease and other neurodegenerative disorders has been fully documented ${ }^{(8)}$. Quercetin is a natural flavonoid found abundantly in almost all edible vegetables and fruits such as red onion, common onion, cranberry, blueberry[Figure 1] ${ }^{(8)}$. Intake of a quercetin-rich diet is highly encourage and is positively correlated with health improvement ${ }^{(10)}$. It can also be taken as dietary supplement with daily recommended doses of 200-1200 mg as well as a nutraceutical through functional foods with a concentration range of 10$125 \mathrm{mg}$ per serving ${ }^{(11)}$. Several studies suggest quercetin therapeutic potential and its derivatives to prevent and treat various chronic diseases, including cardiovascular, neurodegenerative, and cancer ${ }^{(12-14)}$.

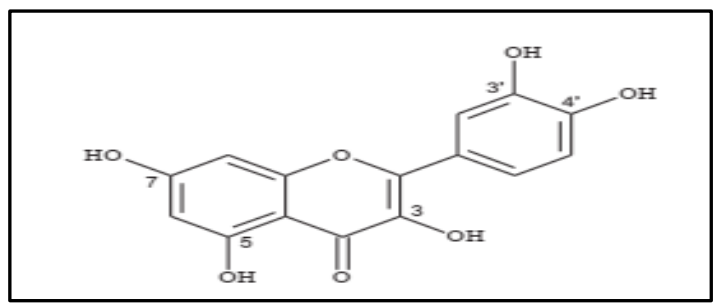

Figure 1. Structure of Quercetin

Lead $(\mathrm{Pb})$ is one of the most abundant heavy metal pollutants in the environment and it's considered to be one of the most hazardous chemicals for humans and animals health ${ }^{(15)}$.

${ }^{1}$ Corresponding author E-mail: ssskatsayal@gmail.com

Received: 6/12/ 2020

Accepted: 22/3 /2021

Published Online First: 2021-12-11

Iraqi Journal of Pharmaceutical Science 
Lead exposure has been attributed to several clinical symptoms including arthritis, renal dysfunction, birth defects, mental retardation, psychosis, hyperactivity, autism and brain damage (16). And, several neurodegenerative disorders such as Huntingtons syndrome, Parkinson and Alzheimer diseases models were simulated in drosophila ${ }^{(17-19)}$, the organism has contributed significantly to the understanding of processes affecting metal toxicity ${ }^{(20)}$. It is therefore considered to be a useful model species for the investigation of biological reactions to toxic chemicals ${ }^{(21,22,15)}$, with its genes having many structurally and functionally preserved homologies to humans ${ }^{(23)}$. This study aimed to determine the effect of short-term exposure to acetylcholinesterase activity in relation to oxidative damage associated with Alzheimer's disease pathogenesis and the role of functional foods in improving these oxidative processes.

\section{Materials and Methods}

The Randox Protein Kit was Purchased from Medicom, State of Jos Plateau. Sigma Aldrich purchased 1-chloro-2, 4-dinitrobenzene (CDNB), and 5-dithiobis (2-nitrobenzoic acid)(DTNB) (St Louis, MO). Harwich strain flies were collected from Jos, Plateau State, African Center of Excellence for Phytomedicine Research and Development.

\section{Grouping and Treatments}

The flies were cultured on the standard Drosophila culture medium consisting of corn flour, brown sugar, yeast, agar, and propionic acid as a mould inhibitor. The culture was maintained at $25 \pm 2{ }^{\circ} \mathrm{C}$ in controlled 12 hour light and darkness. Lead acetate $(300 \mu \mathrm{L})$ was used as model pollutant and the flies were divided into four groups. Group one was treated with normal feed containing normal distilled water, group two with quercetin $(100 \mu \mathrm{L})$, group three lead acetate $(300 \mu \mathrm{L})$ and group four with the combination of lead acetate and quercetin in stated concentration. The flies were anesthetized to ice and homogenized to $100 \mathrm{mM}$ phosphate buffer saline (pH7.4) in 1:10 volumes. The flies were centrifugated with a cold centrifuge at $4000 \mathrm{rpm}$.

\section{Determination of total Thiol content}

The total thiol content was calculated using Ellman's process [24]. The reaction mix comprised $510 \mu \mathrm{L}$ potassium phosphate buffer (0.1 M, PH 7.4), $25 \mu \mathrm{L}$ sample, and $30 \mu \mathrm{L}$ DTNB $(10 \mathrm{mM})$. The reaction mixture was incubated for $30 \mathrm{~min}$ at room temperature, the optical density was taken at $412 \mathrm{~nm}$ and total thiol content was expressed in $\mathrm{mmol} / \mathrm{mg}$ protein. Standard glutathione was used for standard calibration. According to the manufacturers' instructions, the protein concentration of homogenates was determined with the total protein kit (Randox). The data were measured with blank and blank samples, and the results were all corrected with protein content.

\section{Determination of Glutathione-S-transferase (GST) activity}

Activity of Glutathione-S-transferase (GST; EC 2.5.1.18) was calculated using Habig and Jacoby method [25], with 1-chloro-2, 4dinitrobenzene (CDNB) as substrate. The reaction mix consist solution A $600 \mu \mathrm{L}, \quad(20 \mu \mathrm{L} 0.25 \mathrm{M}$ potassium phosphate buffer, $\mathrm{pH} 7.0$ with $2.5 \mathrm{mM}$ EDTA and $510 \mu \mathrm{L} 0.1 \mathrm{M} \mathrm{GSH}$ at $25^{\circ} \mathrm{C}$ ), $60 \mu \mathrm{L}$ sample (1:5 dilution) and $30 \mu \mathrm{L} 25 \mathrm{mM}$ CDNB. Optical density was calculated at $340 \mathrm{~nm}$ at $10 \mathrm{~s}$ intervals for $2 \mathrm{~min}$ (Jenway). The data were expressed in $\mathrm{mmol} / \mathrm{min}$ using the $9.6 \mathrm{mM} 1 \mathrm{~cm} 1$ molar extinction coefficient of the GST-formed GSDNB conjugate.

\section{Determination of Catalase (CAT) Activity}

The activity of catalase (CAT; EC 1.11.1.6) was monitored using a process of Aebi [26]. Reaction mix containing $100 \mathrm{~mL}$ of potassium phosphate buffer ( $\mathrm{pH} 7.0$ ), $194 \mathrm{~mL}$ of solution A (300 $\mathrm{mM} \mathrm{H}_{2} \mathrm{O}_{2}$ ). About $10 \mu \mathrm{L}$ of sample was added to $590 \mu \mathrm{L}$ of solution $\mathrm{A}$ and the clearance of $\mathrm{H}_{2} \mathrm{O}_{2}$ was monitored using $240 \mathrm{~nm}$ wavelength at $25^{\circ} \mathrm{C}$. Catalase activity was expressed as in mmol of $\mathrm{H}_{2} \mathrm{O}_{2}$ consumed/min

\section{Determination of Acetylcholinesterase Activity}

Acetylcholinesterase activity was monitored following the method described by Ellman et al., ${ }^{(27)}$. The reaction mixture contain 285 $\mu \mathrm{l}$ of distilled water, $180 \mu \mathrm{l}$ of $100 \mathrm{mM}$ potassium phosphate buffer (pH7.4), $60 \mu \mathrm{l}$ of $10 \mathrm{mM}$ DTNB, and $15 \mu \mathrm{l}$ of sample, $60 \mu \mathrm{l}$ of $8 \mathrm{mM}$ acetylthiocholine were added. The change in absorbance was monitored at $412 \mathrm{~nm}$ for $2 \mathrm{~min}$ at 10 $\mathrm{s}$ intervals, using a UV Spectrophotometer. The enzyme activity was expressed as $\mathrm{micromole} / \mathrm{min} / \mathrm{mg}$ of protein.

Molecular docking studies

The crystal

structure of acetylcholinesterase was obtained from the protein database file $4 \mathrm{EXY}$. The file was prepared by extracting solvent molecules, co-crystallized ligands (donepezil) and configured using Chimera v 1.1 to model physiological conditions ${ }^{(28)}$. Added polar hydrogen and allocated partial charges to the regular residue using Gasteiger partial charge means all the hydrogen atoms are specifically represented. However, the most favorable binding interactions were ascertained using AutoDock Vina. The docking complex interactions were analyzed visually using Discovery Studio 2017 R2 Client (v17.2.0.16349). AutoDock Vina uses conformation-dependent algorithms to rate interactions binding ligands:

$\mathrm{c}=\sum_{i<j}^{n} f_{t i t j}\left(r_{i j}\right)$

\section{In silico pharmacokinetic and toxicity studies Some ADMET properties of quercetin was evaluated using ADMETlab platform}


(http:/admet.scbdd.com/webserver/ADMETpredicti on) as defined by (29) Jie et al. (2018). The physicochemical properties, distribution, and toxicity evaluation was performed using the canonical SMILE format of the respective compounds derived from the PubChem database. The study is based on a thorough exploration of a systematic database of 288,967 entries from different sources, including peer-reviewed journals, ChEMBL, EPA, and DrugBank databases. All data were divided into six groups (basic, A, D, M, E, and T) and a set of subclasses by their endpoint meanings. Molecular Operating Environment (MOE, version 2016) has tested and evaluated the corresponding necessary details and experimental values of these entries, forming the basis for predicting a new compound based on computational similarity check.

\section{Statistical analysis}

The findings were shown as mean \pm SEM. GraphPad Prism 5 software was used for Statistical analysis. The disparity in treatment groups was examined using One way ANOVA, and the difference was considered significant at $\mathrm{P}<0.05$. Microsoft Office Excel 2007 used to plot graphs.

\section{Results}

\section{Antioxidant biomarkers}

Treatment with lead acetate induced a sharp decrease in total thiol content [Figure 2]. Coadministration of lead acetate and quercetin was able ameliorate the decrease in total thiol content observed in a group treated with lead acetate alone. The activity of glutathione-S-transferase and catalase was also shown to be compromise by administration of lead acetate [Figure 3 and 4]. Quercetin alone as well as in co-administration with lead acetate improve the decline in activity of both glutathione-S-transferase and catalase.

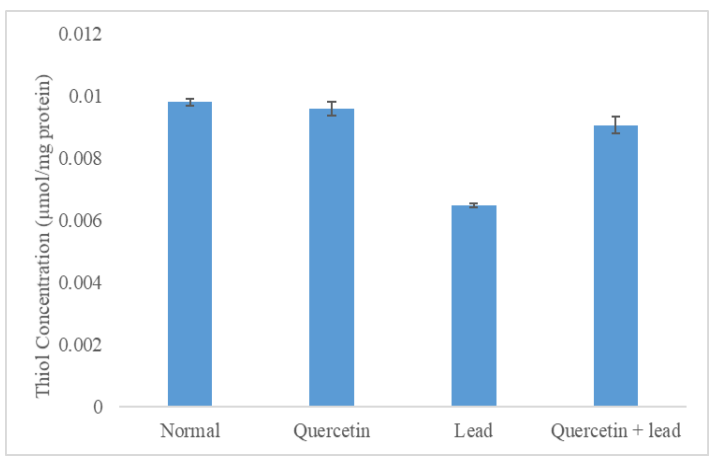

Figure 2. Effects of Quercetin on Total Thiol Concentration in Lead Treated Drosophila.* = significant is when compared to normal control group.

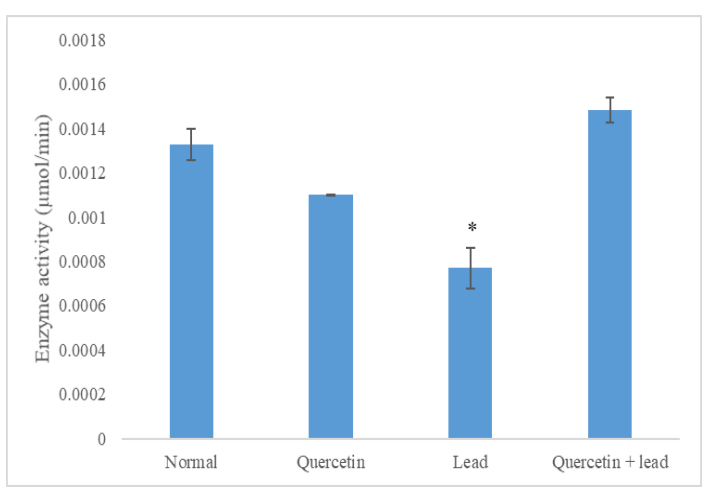

Figure 3.Effects of Quercetin on Glutathione-Stransferase Activity in Lead Treated Drosophila Melanogaster. $*=$ difference significant when compared to normal control group.

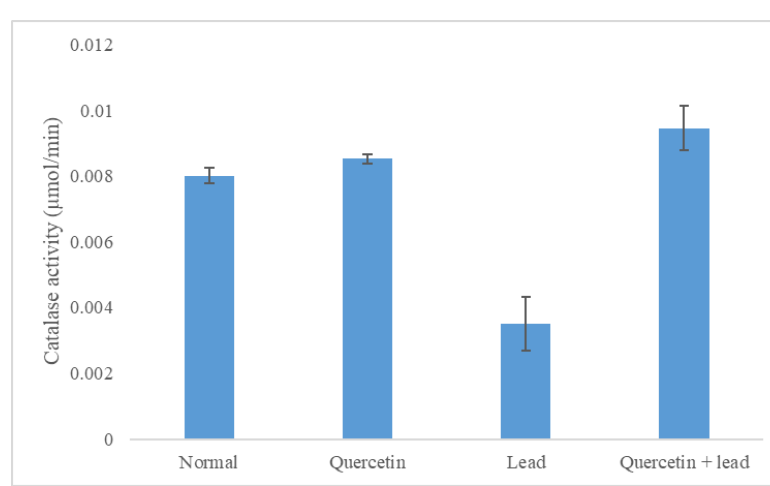

Figure 4. Effects of Quercetin on Catalase Activity in Lead Treated Drosophila Melanogaster.

* = difference significant when compared to normal control group.

\section{Acetylcholinesterase activity}

The activity of acetylcholinesterase was drastically reduce due to lead acetate exposure, while co-administration with quercetin resuscitate its activity to optimum [Figure 5]. The activity of the enzyme has also improved after administration of quercetin alone.

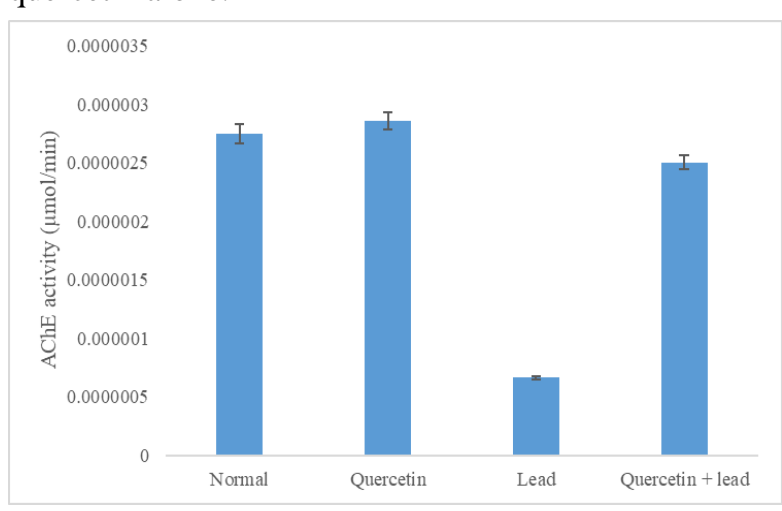

Figure 5.Effects of Quercetin on Acetylcholinesterase Activity in Lead Treated Drosophila Melanogaster. $*=$ difference significant when compared to normal control group. 
In silico Pharmacokinetic and Molecular Docking Studies

Pharmacokinetic showed quercetin to confer moderate aqueous and non-polar solubility, high therapeutic index, non-mutageni $\mathrm{c}$ and hepatotoxic properties as depicted in Table 2. It also demonstrated excellent permeability based on epithelial colorectal adenocarcinoma cell-line (caco2-), while compound could remain in the body due to their low clearance rate. Molecular docking studies reveal very motivating binding energy and inhibition constants of different interactions, as shown in Table 3. The interactions included the polar and non-polar amino acid residue present in the acetylcholinesterase binding pockets [Figure 68]. Furthermore, there were hydrogen, hydrophobic, and other non-conventional interfaces between the compounds and the intended receptor.

Table 2. In silico Toxicity and Pharmacokinetic Prediction Profile on Quercetin and its.

\begin{tabular}{|c|c|c|c|c|}
\hline \multirow[t]{2}{*}{ Category } & \multirow[t]{2}{*}{ Property (unit) } & \multicolumn{2}{|c|}{$\begin{array}{l}\text { Predicted } \\
\text { Result }\end{array}$} & \multirow[t]{2}{*}{ Inference / Reference Range } \\
\hline & & QCN & DPL & \\
\hline \multirow[t]{2}{*}{$\begin{array}{l}\text { Basic } \\
\text { physicochemical } \\
\text { property }\end{array}$} & $\begin{array}{l}\text { LogP (partition } \\
\text { coefficient ) (log mol/L) }\end{array}$ & 1.99 & 2.59 & $\begin{array}{l}\text { LogP <0: poor lipid bilayer } \\
\text { permeability. } \\
\text { LogP > 3: poor aqueous solubility. }\end{array}$ \\
\hline & $\begin{array}{l}\text { LogD7.4 (Distribution } \\
\text { coefficient D) (log mol/L) }\end{array}$ & 0.14 & 0.79 & $\begin{array}{l}<1 \text { : High Solubility; } \\
1 \text { to } 3 \text { : Moderate Solubility; } \\
\geq 3 \text { : Low Solubility. }\end{array}$ \\
\hline Absorption & $\begin{array}{l}\text { Papp (Caco-2 } \\
\text { permeability) }(\mathrm{cm} / \mathrm{s})\end{array}$ & -6.17 & -5.12 & Optimal: higher than -5.15 or -4.70 \\
\hline \multirow[t]{2}{*}{ Distribution } & $\begin{array}{l}\text { PPB (Plasma protein } \\
\text { binding) }(\%)\end{array}$ & 94.9 & 87.3 & $\begin{array}{l}90 \% \text { : Significant with drugs that are } \\
\text { highly protein-bound and have a low } \\
\text { therapeutic index. }\end{array}$ \\
\hline & $\begin{array}{l}\text { BBB (Blood brain barrier) } \\
(\%)\end{array}$ & 0.24 & 0.17 & $\begin{array}{l}\geq 0.1: \text { BBB positive. } \\
<0.1: \text { BBB negative. }\end{array}$ \\
\hline \multirow[t]{2}{*}{ Excretion } & Clearance $(\mathrm{mL} / \mathrm{min} / \mathrm{kg})$ & 2.05 & 1.89 & $\begin{array}{l}\text { Range: }>15 \text { high; } \\
5<\mathrm{Cl}<15 \text { : moderate; } \\
<5 \text { : low. }\end{array}$ \\
\hline & T1/2 (Half life) $(\mathrm{H})$ & 0.20 & 1.08 & $\begin{array}{l}\text { Range: }>8 \mathrm{H} \text { : high; } \\
3 \mathrm{~h}<\mathrm{Cl}<8 \mathrm{H} \text { : moderate; } \\
<3 \mathrm{H} \text { : low. }\end{array}$ \\
\hline \multirow[t]{2}{*}{ Toxicity } & $\begin{array}{l}\text { H-HT (Human } \\
\text { Hepatotoxicity) }\end{array}$ & 0.56 & 0.64 & $\begin{array}{l}>0.5: \text { HHT positive } \\
<0.5: \text { HHT negative }\end{array}$ \\
\hline & $\begin{array}{l}\text { AMES (Ames } \\
\text { mutagenicity) }\end{array}$ & 0.74 & 0.08 & $\begin{array}{l}>0.5: \text { Positive } \\
<0.5: \text { Negative } \\
\end{array}$ \\
\hline
\end{tabular}

QCN = Quercetin and DPL = Donepezil

Table 3. Binding Energy and inhibition binding Constant of Quercetin against Acetylcholinesterase Receptor bound to Donepezil (4EXY).

\begin{tabular}{|l|c|c|}
\hline \multicolumn{1}{|c|}{ Quercetin } & Binding Energy $(\boldsymbol{\mu M})$ & Inhibition Binding Constant $(\mathbf{k c a l} / \mathbf{m o l})$ \\
\hline Quercetin & -10.1 & 0.981 \\
\hline Donepezil & -10.6 & 0.981 \\
\hline
\end{tabular}




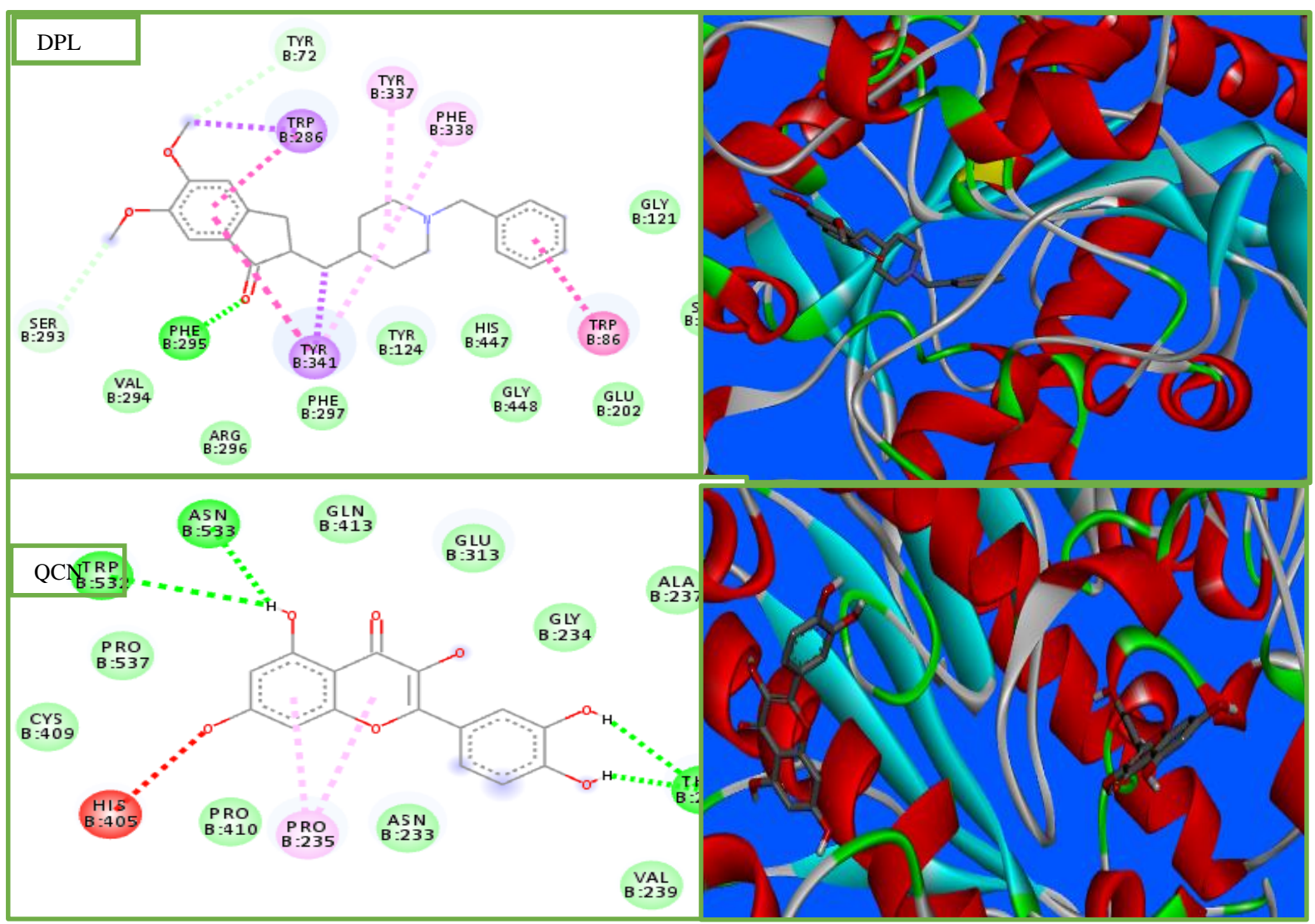

\section{Interactions}

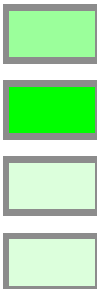

van der Waals

Conventional Hydrogen Bond

Carbon Hydrogen Bond

Pi-Donor Hydrogen Bond

Figure 8. Amino acids interactions and 3D conformations of quercetin within the binding pocket of acetylcholinesterase. QCN = Quercetin, DPL = Donepezil.

\section{Discussions}

The function of oxidative stress and cholinesterase activity is one of the most verified hypotheses and try to explain the pathophysiology associated with neurodegeneration ${ }^{(30,31)}$. Oxidative radicals have been documented to play a critical role in promoting cellular damage, particularly in fatty tissues, and have been involved in neurodegenerative disease pathogenesis (32). Intensifying evidence indicates that oxidative radicals may play a crucial role in the brain of patients with neurodegenerative diseases (33,34). Upregulation of antioxidant biomolecules due to administration of quercetin observed in this study could be explained from two viewpoint. The first point could be linked to quercetin ability as an excellent antioxidant/metal chelator to donate a proton thereby quenching oxidative chain reaction (35). And the second reason is that quercetin might possess the ability to induce gene expression for the production of catalase, thiol and glutathione-Stransferase. Hydroxyl, carbonyl groups and resonance activity in flavonoids and other phytocompounds were detailed to be responsible for their antioxidant and chelation properties $(36,37)$. Marija et al., (11) asserted that in most cases the capacity for antioxidants is directly proportional to the number of free hydroxyl groups.

Acetylcholinesterase (AChE) is an enzyme of the $\alpha / \beta$ hydrolase-fold superfamily with a critical role in synaptic neurotransmission ${ }^{(38,39)}$. It is responsible for terminating the nerve impulses in cholinergic and neuromuscular synapses by separating the acetylcholine neurotransmitter into choline and acetate $^{(40,41)}$. This influence results in downstream 
modulation of striatal and hippocampal neurons of significance to motion, learning, and memory ${ }^{(42)}$. Hence given the aforementioned global advocacy for expanded use of nutraceuticals in managing various diseases, including neurodegenerative disorders, this study was conducted to highlight the efficacy of certain food-based phytocompounds; with Alzheimer's disease, the activity level of AChE enzyme declines and the level of butyrylcholinesterase activity increases in the brain (3). Dual inhibition strategy on these enzymes has been reported most recently to increase the effectiveness of the treatment rather than to restore the initial balance. In this attempt, like in many current approach, we attempt to focus on restoration of the initial balance between acetylcholinesterase and butyrylcholinesterase by reactivation of acetylcholinesterase activity. Finding in this work revealed quercetin to confer the potentials to induce the activity of acetylcholinesterase. This finding is in agreement with many works reported in the earlier studies ${ }^{(43)}$. Ulrike et al., (44) affirmed that development of bivalent ligands that occupy both the active and the peripheral site of acetylcholinesterase might be more beneficial for treatment of Alzheimer's disease than simple inhibition of the acetylcholine hydrolysis. Molecular docking studies revealed the structures of quercetin could be potential acetylcholinesterase reactivators based on their binding site and activation constant. The activation binding process was validated by identifying the co-crystallized AChE inhibitor donepezil. Donepezil bind to acetylcholinesterase through different kinds of interactions which essentially involved Phe295 and many other amino acid residues such as Trp286, Trp341, Trp81, Val294, Gly121, Arg296, Phe297, Tyr124, His447, Gly448, Glu202 and Ser203, respectively. Quercetin bind to acetylcholinesterase through various amino acid residue including those involved in its interaction with donepezil. Omamuyovwi and Augustine [38], shows Kolaviron may be a novel herbal, medicinal product to treat neurodegenerative disorders associated with dysregulated cholinergic neurotransmitter systems. These compounds were further predicted to safe and physicochemically promising bioactive molecules. This finding correlate with the work reported by Aliyu et al., ${ }^{(4)}$, who predicted a great Pharmacokinetic potentials of some phytocompounds. Interestingly, quercetin could be transferred efficiently to their different targets via the bloodstream as proof of plasmabinding abilities.

\section{Conclusion}

Based on the present work, quercetin shows potentials ability to restore acetylcholinesterase activity in lead induced damage in drosophila melanogaster species. It's further demonstrated the ability of up regulate the production of biological antioxidant molecules. By correlating the docking outcomes with experimental data obtained, it can be suggested that presence of quercetin alongside many other phytocompounds in food could be reasonable in the management of Alzheimer's diseases and related neurodegenerative disorders. Further studies should be performed on other phytocompounds for the treatment of neurodegenerative disorders.

\section{Declaration of interest}

The authors declared no competing interest with regards to the publication of this paper.

\section{Funding}

No funding was received from any funding bodies.

\section{Acknowledgement}

The authors wish to acknowledge the contributions of all technologies in Biochemistry Department Ahmadu Bello University Zaria for their assistance and guidance towards successful completion of this work. We also wish to appreciate Mrs. Maryam Aliyu of Biochemistry Department Bayero University Kano for improving the quality of this manuscript.

\section{Reference}

1. Du, X., Wang, X., Geng, M., Alzheimer's disease hypothesis and related therapies. Transl. Neurodegener. 2018.7 (1), 2

2. Lleo A, Greenberg SM, Growdon JH: Current pharmacotherapy for Alzheimer's disease. Ann. Rev. Med. (2006) 57:513-533

3. Kumar, S., Dual inhibition of acetylcholinesterase and butyrylcholinesterase enzymes by allicin. Indian J. Pharmacol. 2015. 47 (4), 444-446.

4. Ganeshpurkar, A., Singh, R., Gore, P.G., et al., Structure-based screening and molecular dynamics simulation studies for the identification of potential acetylcholinesterase inhibitors. Mol. Simul. 2019.30, 1-7.

5. Liston, D.R., Nielsen, J.A., Villalobos, A., et al., Pharmacology of selective acetylcholinesterase inhibitors: implications for use in Alzheimer's disease'. Eur. J. Pharmacol.2004. 486 (1), 9-17.

6. Akinori A, Yuki T, Toshiaki K and Yasuhiko I. Mechanisms of Neuroprotective Effects of Nicotine and Acetylcholinesterase Inhibitors: Role of $\alpha 4$ and $\alpha 7$ Receptors in Neuroprotection. J Mol Neurosci (2010) 40:211-216 DOI 10.1007/s12031-009-9236-1

7. Petersen, R. C., Thomas, R. G., Grundman, M., Bennett, D., Doody, R., Ferris, S., ... \& Pfeiffer, E. Vitamin E and donepezil for the treatment of mild cognitive impairment. New England Journal of Medicine, (2005). 352(23), 2379-2388.2

8. Doody RS, Stevens JC, Beck C, et al. Management of dementia (an evidence-based review): report of the Quality Standards 
Subcommittee of the American Academy of Neurology. Neurology 2001;56:1154-1166

9. Bhagwat, S., Haytowitz, D. B., \& Holden, J. M. USDA database for the flavonoid content of selected foods, Release 3.1. US Department of Agriculture: Beltsville, MD, USA (2014).

10. D'Andrea, G. Quercetin: A flavonol with multifaceted therapeutic applications? Fitoterapia, (2015). 106, 256-271.

11. Marija L, Ivana $B$, Nataša $S$, Diandra $P$, Tatjana M, Kristina B, Dejan O, Neda M. Antioxidant and anti-inflammatory activities of quercetin and its derivatives. Journal of Functional Food, (2018). 40, 68-75.

12. Panche AN, Diwan AD, Chandra SR. Flavonoids: an overview. J Nutr Sci. 2016;5:115

13. Serban, M. C., Sahebkar, A., Zanchetti, A., Mikhailidis, D. P., Howard, G., Antal, D., ...Banach, M. Effects of quercetin on blood pressure: A systematic review and metaanalysis of randomized controlled trials. Journal of the American Heart Association, (2016). 5, e002713.

14. Bakhtiari M, Panahi Y, Ameli J, Darvishi B. Protective effects of flavonoids against Alzheimer's disease-related neural dysfunctions. Biomed Pharmacoth. 2017;93:218-229.

15. Wang L, Zhou C, He Z, Wang Z-G, Wang J-L, et al. Wolbachia Infection Decreased the Resistance of Drosophila to Lead. PLoS ONE 7(3): (2012) e32643. doi:10.1371/journal.pone.0032643

16. Brochin, R.; Leone, S.; Phillips, D.; Shepard, N.; Zisa, D.; Angerio, A. The Cellular Effect of Lead Poisoning and Its Clinical Picture. Georg. Undergrad. J. Health Sci. 2008, 5, 1-8.

17. Overk, C.R.; Masliah, E. Pathogenesis of synaptic degeneration in Alzheimer's disease and Lewy body disease. Biochem. Pharmacol. 2014, 88, 508-516

18. Baig, S.S.; Strong, M.; Quarrell, O.W. The global prevalence of Huntington's disease: A systematic review and discussion. Neurodegener. Dis. Manag. 2016, 6, 331-343.

19. Schneider, S.A.; Obeso, J.A. Clinical and pathological features of Parkinson's disease. Curr. Top. Behav. Neurosci. 2015, 22, 205220.

20. Pablo C, Javier G, Noelia S, José V L and María D M. Drosophila melanogaster Models of Metal-Related Human Diseases and Metal Toxicity. Int. J. Mol. Sci. 2017, 18, 1456

21. Alexander, E. M., Aguiyi, J. C., Mdekera, I. W., Ogwu, O. S., Imoleayo, O. O., Ugokwe, C. V., \& Pam, D. The Climbing Performance, Neuromuscular Transmitter (ACHE) Activity, Reproductive Performance and Survival of Drosophila melanogaster Fed Diet with
Mangifera indica Cold Aqueous Leaf Extract. Journal of Applied Life Sciences International, 1-11 (2019).

22. Peterson, E.K., Long, H.E. Experimental Protocol for Using Drosophila As an Invertebrate Model System for Toxicity Testing in the Laboratory. J. Vis. Exp. (137), (2018).e57450, doi:10.3791/57450

23. Singh PB, Miller JR, Pearce J, Kothary R, Burton RD, Paro R, James TC, Gaunt SJ. A sequence motif found in a Drosophila heterochromatin protein is conserved in animals and plants. Nucleic Acids Res. 2011;19(4):789-94

24. Ellman GL. Tissue sulfhydryl groups, Arch. Biochem. Biophys. 1959; 82(1):70-77. Available: http://dx.doi.org/10.1016/00039861 (59)90090-6 13650640

25. Habig WH, Jakoby WB. Assays for differentiation of glutathione S-transferases, Methods Enzymol. 1981;77:398-405

26. Aebi H. Catalase in vitro, methods enzymol. 1984; 105:121-126.

27. Ellman GL, Courtney KD, Andres V, Featherstone RM. A new and rapid colorimetric of acetylcholinesterase determination. Biochem Pharmacol. 1961;7:88-95.

28. Pettersen E. F., Goddard T. D., Huang C. C., Couch G. S., Greenblatt D. M., Meng E. C., Ferrin T. E. UCSF Chimera- a visualization system for exploratory research and analysis. J Comput Chem. 25(13): 2004. 1605-12.

29. Jie, D., Ning-Ning, W., Zhi-Jiang, Y., Lin, Z., Yan, C., Defang, O., Ai-Ping, L., Dong-Sheng, C., ADMETlab: a platform for systematic ADMET evaluation based on a comprehensively collected ADMET database. Journal of Cheminformatics, 10:29 2018.

30. St-Pierre, J., Drori, S., Uldry, M., Silvaggi, J. M., Rhee, J., Jäger, S., ... \& Simon, D. K. Suppression of reactive oxygen species and neurodegeneration by the PGC-1 transcriptional coactivators. Cell, 127(2), (2006). 397-408.

31. K. Hensley, M. Mhatre, S. Mou et al., "On the relation of oxidative stress to neuroinflammation: lessons learned from the G93A-SOD1 mouse model of amyotrophic lateralsclerosis," Antioxidants \& Redox Signaling, vol. 8, pp. 2075-2087, 2006.

32. Zewen, L., Tingyang, Z., Alexander, C. Z.,Peter, D. and Li, Z. Oxidative Stress in Neurodegenerative Diseases: From Molecular Mechanisms to Clinical Applications. Oxidative Medicine and Cellular Longevity, (2017), Article ID 2525967, https://doi.org/10.1155/2017/2525967 
33. Nasreena S., Rohaya A., Sumaya H., Bashir A. G. and Rabia H. Oxidative stress in Neurodegenerative diseases. International Journal of Management, Technology And Engineering, 8(VII) (2018). 508-514.

34. Sebastião, A. M., Colino-Oliveira, M., Assaife-Lopes, N., Dias, R. B., \& Ribeiro, J. A. Lipid rafts, synaptic transmission and plasticity: impact in age-related neurodegenerative diseases. Neuropharmacology, 64, (2013). 97107.

35. Morand, C., Crespy, V., Manach, C., Besson, C., Demigné, C., \& Rémésy, C. Plasmametabolites of quercetin and their antioxidant properties. American Journal of Physiology, 275, (1998). R212-R219

36. Maria M. K.,E. Andrea, and O. Justyn. "Properties and Applications of Flavonoid Metal Complexes". Research Advances., 2015. DOI: 10.1039/C5RA05069C

37. Ren, J., Meng, S., Lekka, Ch. E., \& Kaxiras, E. Complexation of flavonoids with iron: Structure and optical signatures. The Journal of Physical Chemistry B, 112, (2008). 18451850.

38. Omamuyovwi M. I. and Augustine U. O. Kolaviron, isolated from Garcinia kola, inhibits acetylcholinesterase activities in the hippocampus and striatum of wistar rats. Annals of Neurosciences, 20(2) 42-46. (2013). doi : 10.5214/ans.0972.7531.200203

39. Taylor, P. The cholinesterases. J. Biol. Chem. 266, (1991)4025-4028.
40. Tripathi A, Srivastava UC. Acetylcholinesterase: a Versatile Enzyme Of Nervous System. Annals of Neurosci. 2008; 15(4): 106-111.

41. Freitas RM, Sousa FCF, Viana gSB, et al. Acetylcholinesterase activities in hippocampus, frontal cortex and striatum of Wistar rats after pilocarpine-induced status epilepticus. Neurosci Letters. 2006; 399: 7678.

42. Volpicelli-Daley LA, Hrabovska A, Duysen $\mathrm{Eg}$, et al. Altered Striatal Function and Muscarinic Cholinergic Receptors in Acetylcholinesterase

Knockout Mice. Mol Pharmacol. 2003; 64: 1309-1316.

43. Oksana G., Xiaotian K., Xiaolin C., Troy W., Donald K. B., Palmer T., Zoran R. and Andrey K. Productive reorientation of a bound oxime reactivator revealed in room temperature X-ray structures of native and VXinhibited human acetylcholinesterase. J. Biol. Chem. 294(27) (2019). 10607-10618. DOI 10.1074/jbc.RA119.008725

44. Ulrike H, Petra K, Vildan A, Josef S and Eva $\mathrm{K}$ Targeting acetylcholinesterase to treat neurodegeneration. Expert Opin. Ther. Targets (2007) 11(2):161-179

45. Aliyu M. Babangida S. Gilead EF. Ibrahim M. Ibrahim BA. Amina IK.....Zakwan SU. In silico prediction on the possible mechanism of action of selected bioactive compounds against breast cancer. In silico pharmacology, 8(4). (2020). https://doi.org/10.1007/s40203-02000057-8

Baghdad Iraqi Journal Pharmaceutical Sciences by bijps is licensed under a Creative Commons Attribution 4.0 International License. Copyrights $\bigodot 2015$ College of Pharmacy - University of Baghdad. 